Original Research Paper

\title{
Investigating the Effect of Heat on Reinforced Concrete Frame Using Finite Element Software
}

\author{
${ }^{1}$ Reza Salehi and ${ }^{2}$ Abbas Akbarpour Nikghalb Rashti \\ ${ }^{1}$ Islamic Azad University, South Branch, Tehran, Iran \\ ${ }^{2}$ Department of Civil Engineering, Islamic Azad University, South Branch, Tehran, Iran
}

\author{
Article history \\ Received: 24-03-2018 \\ Revised: $10-04-2018$ \\ Accepted: 02-05-2018 \\ Corresponding Author: \\ Reza Salehi \\ Islamic Azad university, South \\ Branch, Tehran, Iran \\ Email: salehi.reza14@yahoo.com
}

\begin{abstract}
The present paper examines the effect of heat on the reinforced concrete frame. A concrete frame with a specific geometric dimension has been modeled in ABAQUS finite element software and its loading capacity and other specifications, such as hardness and ductility, have been obtained. Then the concrete frame was heated under temperature 200, 400, 600, 800 and $1000^{\circ} \mathrm{C}$ and load capacities and coefficients were calculated. The purpose of the study is to investigate the effect of heat on the bearing capacity, hardness and ductility of concrete frames under the heat, which is important for the reinforcement of concrete structures against fire. The effect of heating on aggregates, tensions criteria and the modulus of elasticity of the rebar, as well as the strength and modulus of elasticity of concrete, have been applied through the ASTM E119 heating regulation. The results show that with increasing heat temperature, the load capacity of the frame decreases, which is very significant at temperatures of 800 and $1000^{\circ} \mathrm{C}$. Due to the dependence of hardness and ductility on the initial displacement of the submission, the decreasing trend of the frames depends on the yield displacement. In the models under 800 and 1000, the hardness dropped sharply due to the collapse of the system.
\end{abstract}

Keywords: RC Frame, Temperature and Fire, ASTM E119, ABAQUS Program

\section{Introduction}

Fire is a phenomenon that any structure may experience during its useful life. With the expansion of modern urbanization, the potential of fire hazards and the possibility of their occurrence in the structure has also expanded and full safety against fire is impossible. According to a survey conducted after the September 11 incident, reducing the stiffness and resistance were one the important factors in the general destruction of the world-wide buildings of world trade was the property of the structural materials used in these buildings. Concrete structures, despite their relative superiority to steel against fire, can be highly vulnerable. At high temperatures, changes in the properties of concrete and materials such as modulus of elasticity, fracture resistance and the presence of a phenomenon called tightness, which is associated with a decrease in the cross-sectional area of the concrete, increases the displacement of the sites and finally destroys the structure. The stresses that occur in the concrete column during the fire are due to the pressure of the evaporated water in the concrete as well as the stresses due to the expansion. The concrete has been proven to explode at high temperatures. This concrete explosive behavior is added to other hazards during fire.

\section{Tensile and Compressive Behavior of Concrete}

Among the theories presented to explain the behavior of concrete, the two plastic theories and failure mechanism are most adapted to the actual behavior of concrete which had been done by Priestley et al. (1996). In this research, a damaged plastic model (CDP model) for concrete modeling is used.

In addition to the elastic parameters (modulus of elasticity and Poisson coefficient), with the CDP model, the numerical values of the five plastic parameters and the specific parameters representing as follows:

1. The angle of expansion $\varphi$ is the ratio of volume variation to shear strain. The larger of the parameter $\varphi$ values causes more ductility of the concrete 
2. Eccentricity, $\varepsilon$, which gives the rate of approach of the potential function of plastic to its asymptote and by increasing this issue, the curvature will increase at low potentials. The value of the eccentricity is considered as default in the program of 0.1

3. $f_{b 0} / f_{c 0}$; Which is the bi-directional compressive stress ratio to the stress-directed stress-strain, which in the experiments is usually between $1 / 1$ and $1 / 16$

4. K parameter; Which specifies the shape of the yield surface and can range from 0.5 to $1 / 1$

5. Viscosity parameter, $\mu$ introduced by Priestley et al. (1996); It shows the time of viscoelastic system. Some problems of non-convergence can be solved by standardizing and adjusting the visco-plastic equations and thus allowing stresses to drop out of the surface of tension

The parameters for the behavior of concrete plastics are shown in Table 1.
Sayyar et al. $(2015 ; 2017)$ did numerical modeling using research edition of MATLAB toolbox to model the CDP behavior for different concrete strength which used various equations based on compressive strength and its ultimate strain. He (2018) also validated the CDP output with modeling and analysis by ABAQUS software in the part of RC columns, beams under various extreme loading condition. In his study, the tensile and compressive behavior of damage parameter has been calculated, too. The general compressive and tensile graphs have divided into elastic and plastic parts which only the plastic part could be used for ABAQUS modeling. Moreover, Fallahi et al. (2018) has used the CDP model introduced by Sayyar et al. (2018) to validate his infilled RC frame. His result indicated very good accuracy with experimental tests.

Specifications of compressive and tensile strength of $24 \mathrm{MPa}$ concrete used in the middle areas of beam and column and the compressive strength and tensile strength of concrete $48 \mathrm{MPa}$ used in the beam-column connection are in Fig. 1 and 2.

Table 1: Parameters required for the CDP model to define the behavior of concrete plastics

\begin{tabular}{llccc}
\hline Dilation angle & Eccentricity & $f_{b 0} / f_{c 0}$ & $\mathrm{~K}$ & Viscosity Parameter \\
\hline 33 & 0.1 & 1.12 & 0.66 & 0.001 \\
\hline
\end{tabular}
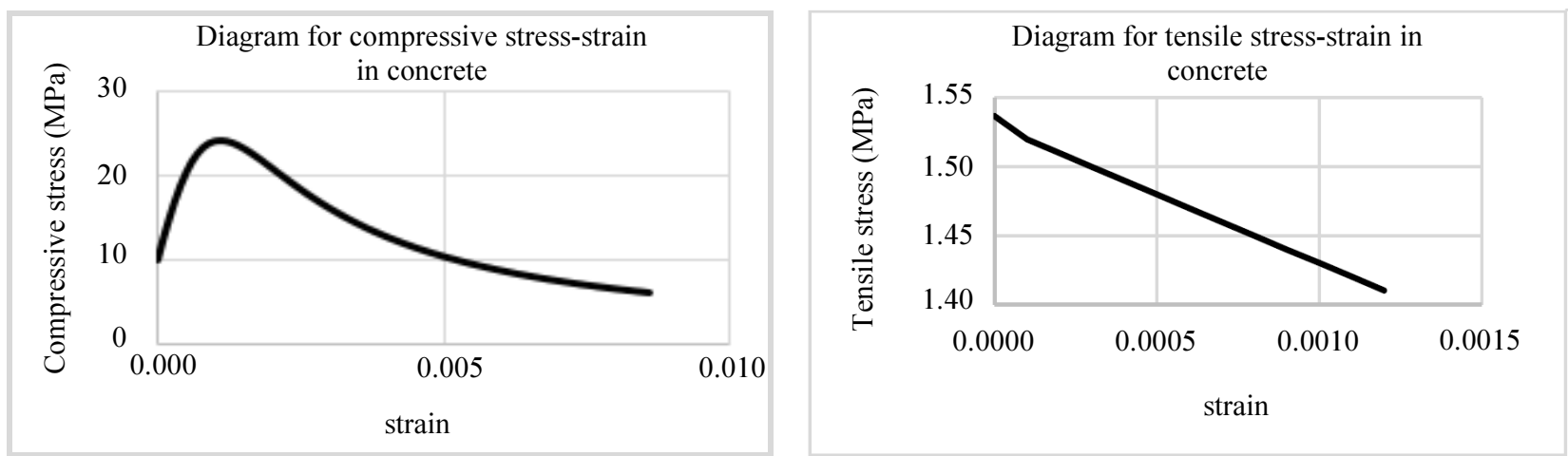

Fig. 1: Compressive and tensile strength of $24 \mathrm{MPa}$ concrete
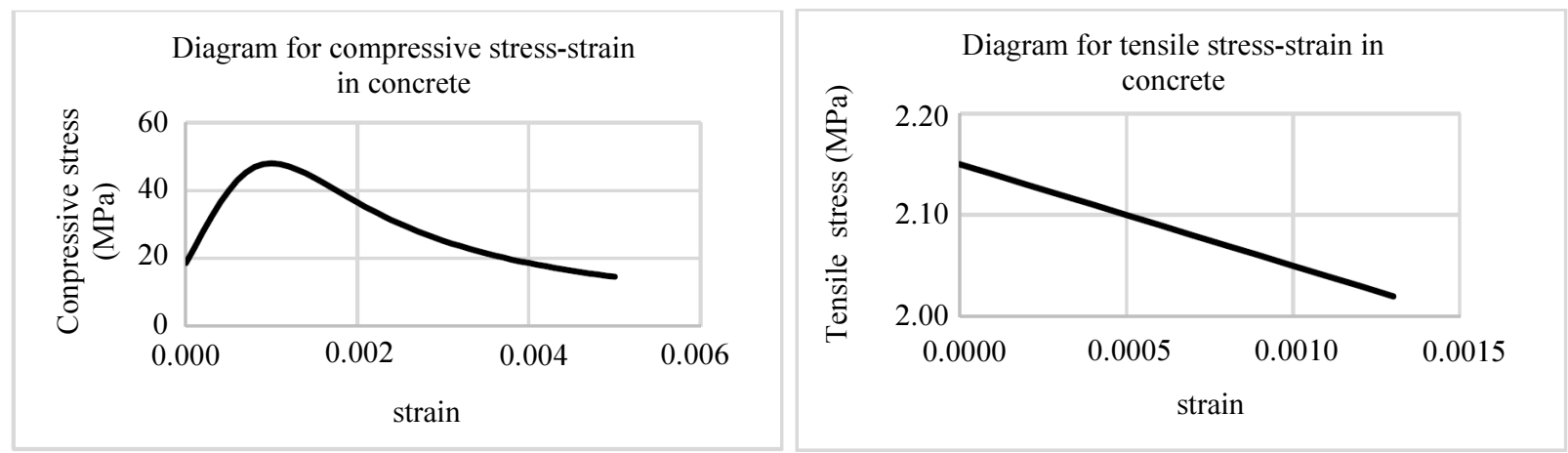

Fig. 2: Compressive and tensile strength of $48 \mathrm{MPa}$ concrete 


\section{The Effect of Temperature and Fire on RC-Components}

The variations in the heat stress tolerance are as follows in Equation 1:

$$
\begin{aligned}
& F_{y}=F_{y 0}\left(1+\frac{T_{c}}{767 \ln \left(\frac{T_{c}}{1750}\right)}\right) 0<T_{c} \leq 600^{\circ} \mathrm{C} \\
& F_{y}=F_{y 0}\left(\frac{108-\frac{T_{c}}{1000}}{T_{c}-440}\right) 600<T_{c} \leq 1000^{\circ} \mathrm{C}
\end{aligned}
$$

where:

$F_{y}=$ The tension of yield stress of steel at hightemperature

$F_{y_{0}}=$ Yield stress at room temperature

$T_{c}=$ Steel temperature (Celsius)

1. Specification depends on the temperature of the concrete, depending on the type of aggregate present in it. Bangash 958 made a behavioral comparison in this case. Figure 3 shows the effect of temperature on the modulus of elasticity of concrete for 3 types of aggregate (Bangash et al., 2014)
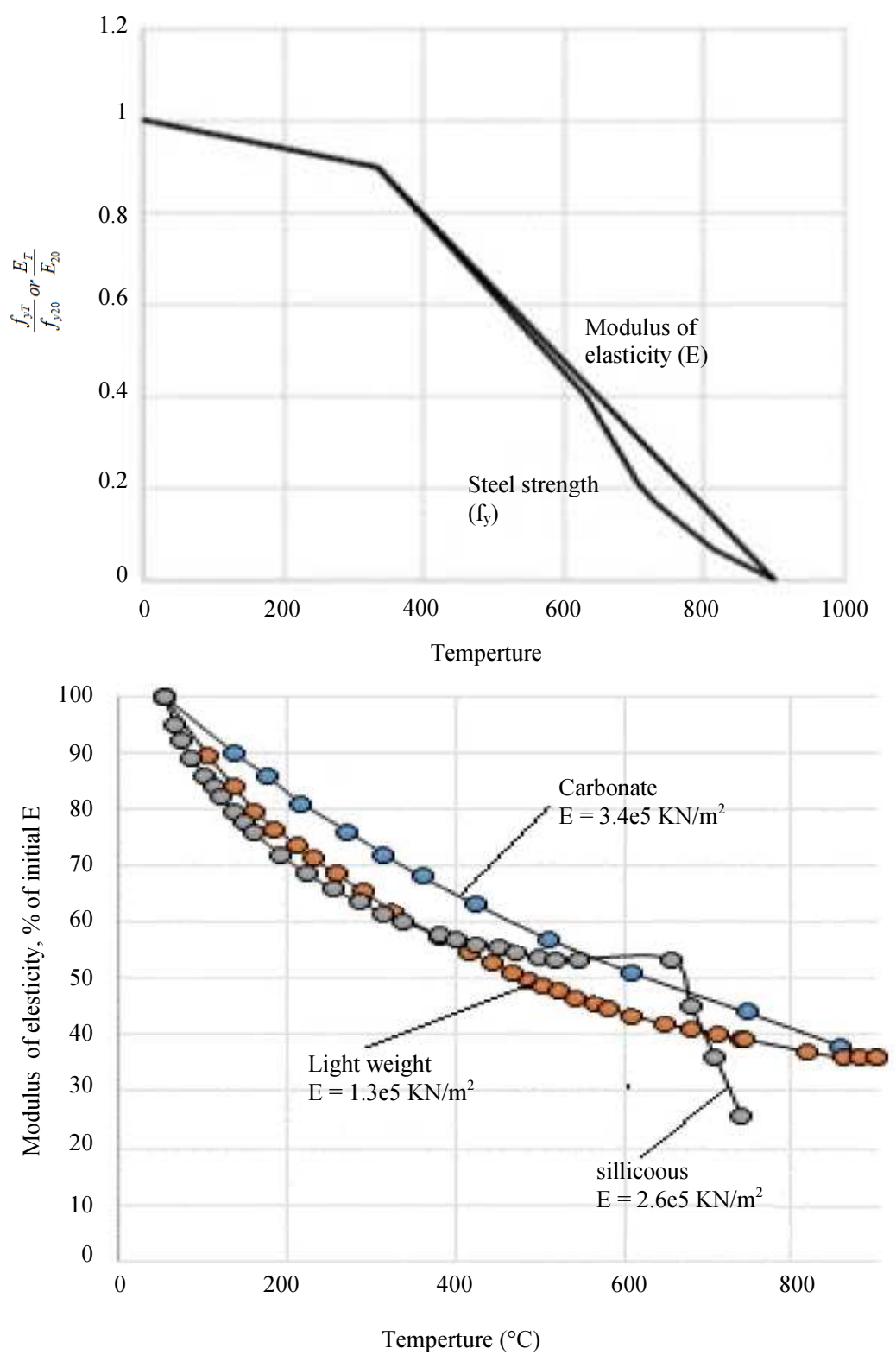

Fig. 3: The relationship between steel profile and temperature (Degrees Celsius) - The effect of heat on the modulus of elasticity of concrete (Bangash et al., 2014) 


\section{Verification}

To test the effect of temperature and accuracy of the results, experimental tests have been done by the Codur (2003). In this verification, concrete columns with $305 * 305 \mathrm{~mm}$ and a height of $3.8 \mathrm{~m}, 4 \phi 25 \mathrm{~mm}$ reinforcements with $420 \mathrm{MPa}$ yield stress was modeled. The stirrup was modeled by $8 \mathrm{~mm}$ diameter bar and the distance of each stirrups was considered $145 \mathrm{~mm}$ at the middle and $75 \mathrm{~mm}$ for both ends in which the steel yield stress for transvers bars was $280 \mathrm{MPa}$. The following Fig. 4 show the details of the sample.

The thermal load in the verification model is applied at a distance of $19.5 \mathrm{~mm}$ from the external aspect of the column and the result is presented in terms of temperature-time. In Fig. 5, the verification graph of the column model is visible under the temperature.
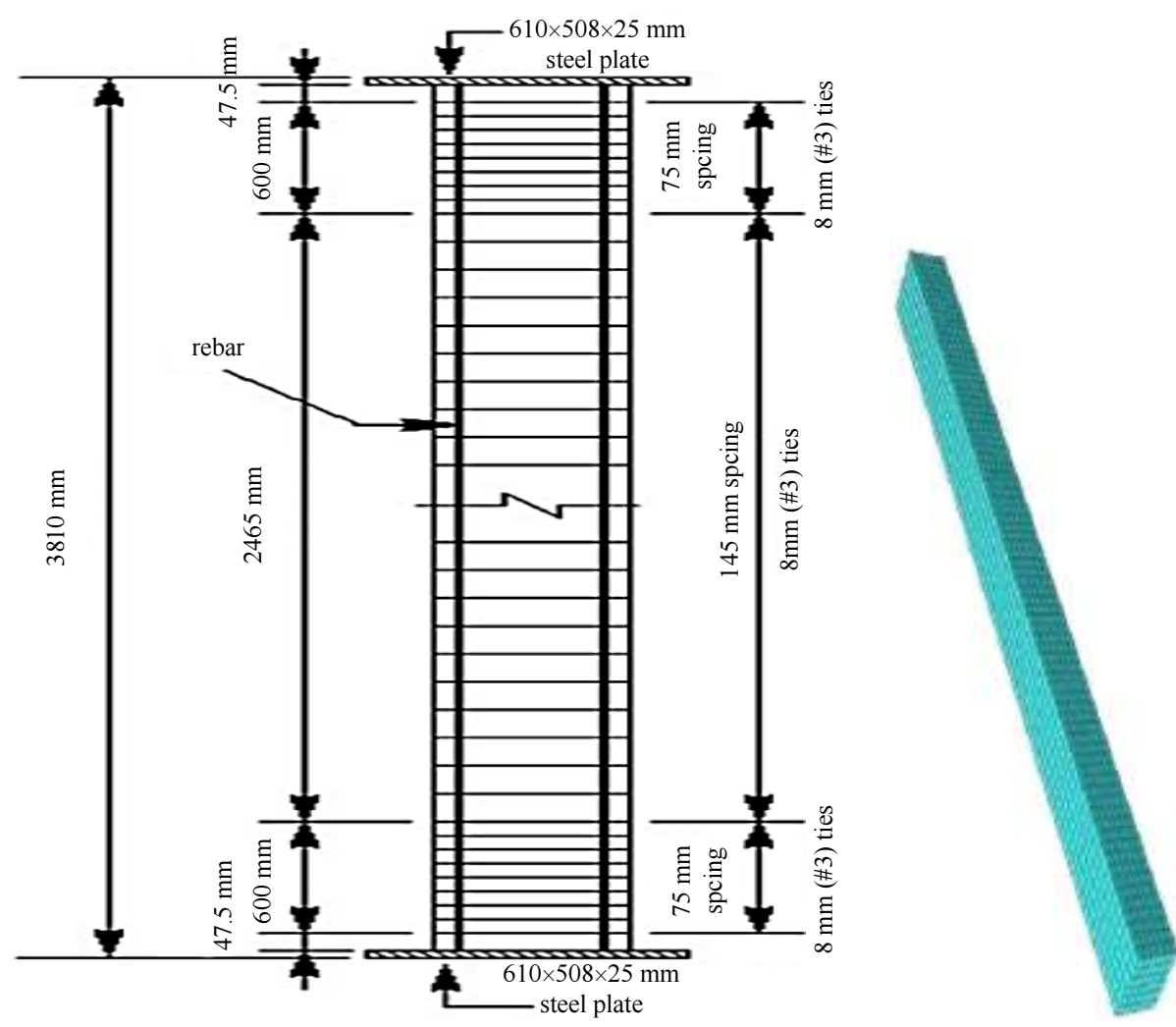

Fig. 4: RC column tested by Kodur et al. (2003)

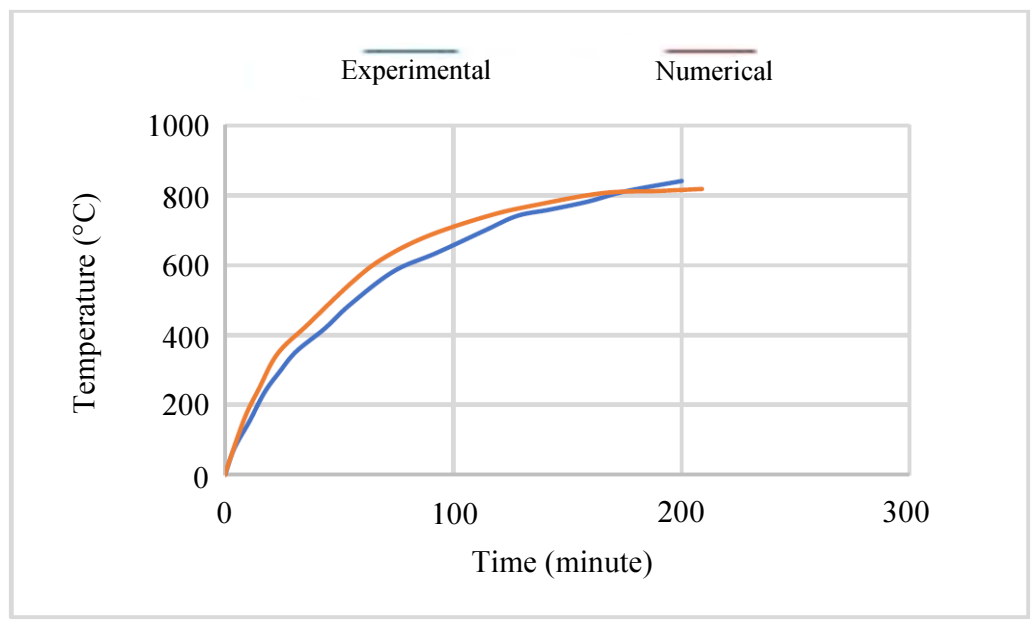

Fig. 5: Comparison of temperature - laboratory and FEM 
Figure 6 shows the frame in which the middle and the interior of that affected by heating. The ambient heat is considered standard and has been analyzed within 10 degrees increments in each step. The model is heated at temperatures of $200,400,600,800$ and 1000 degrees Celsius.

According to Fig. 7 the finite element analysis, the frame without heat exposure has a loading capacity of $65.25 \mathrm{KN}(8)$. Also, at $200^{\circ} \mathrm{C}$, the maximum tolerable force in this frame is $52.58 \mathrm{KN}$.

In Fig. 8, the distribution of the stress and heat in the concrete and rebars can be observed. It can be seen that the heat begins to move from the internal elements of the concrete towards the outer faces. Also, in von Mises stress in the concrete, the distribution of cracks in the upper regions of the beam and especially at the base of the column, is quite clear and it is possible to form a plastic joint in the area of the beam to the column.

The energy-displacement curve of a $400^{\circ} \mathrm{C}$ - model is depicted in Fig. 9. The maximum load capacity of this model was $43 / 77 \mathrm{KN}$ at test conditions. It can be seen that at this temperature, the load capacity of the model has dropped about $8.8 \mathrm{KN}$ at $200^{\circ} \mathrm{C}$.

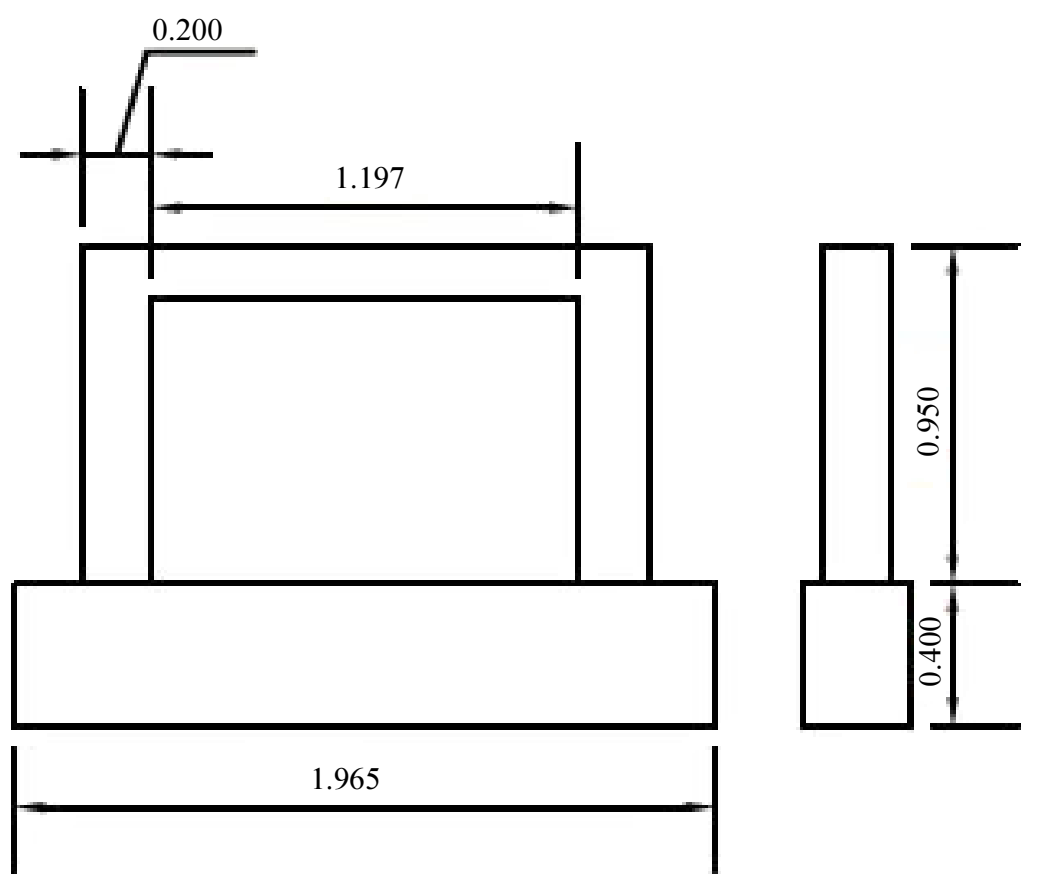

Fig. 6: Geometric dimensions of the frame (Hemmati et al., 2016)

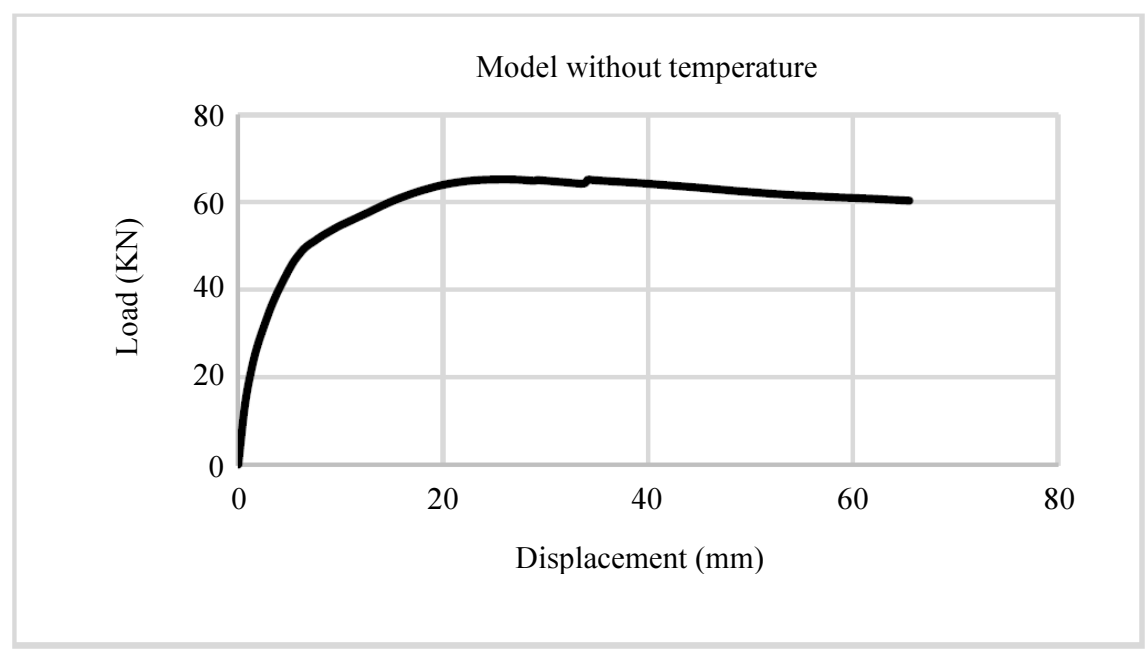




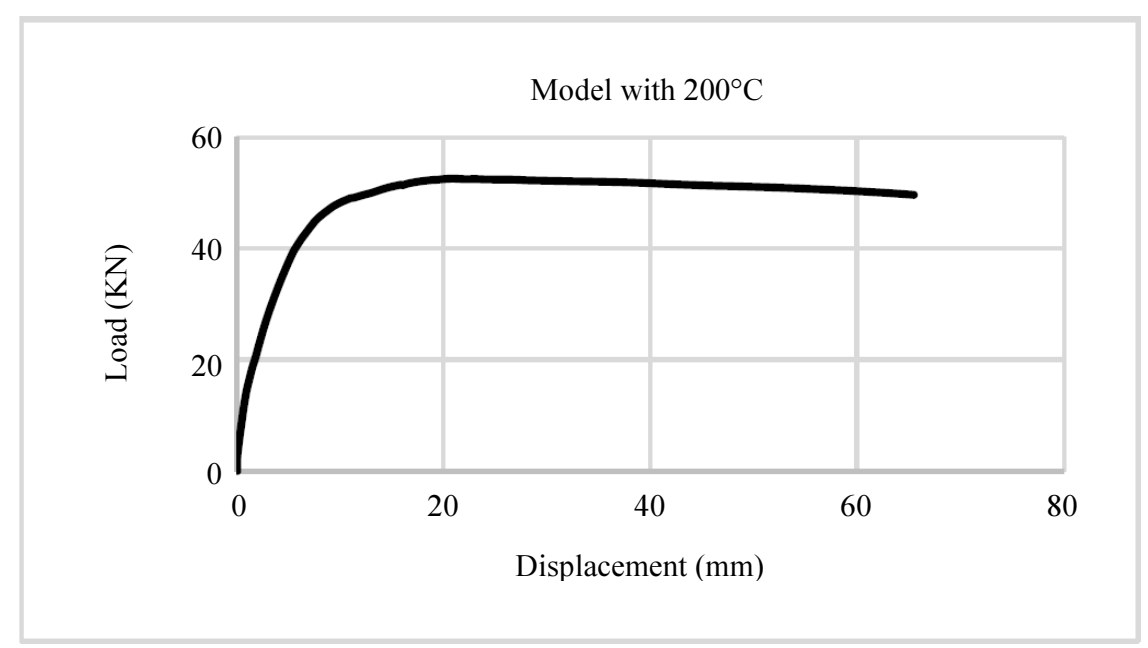

Fig. 7: Load-displacement diagram obtained from the heat-free frame is $200^{\circ} \mathrm{C}$

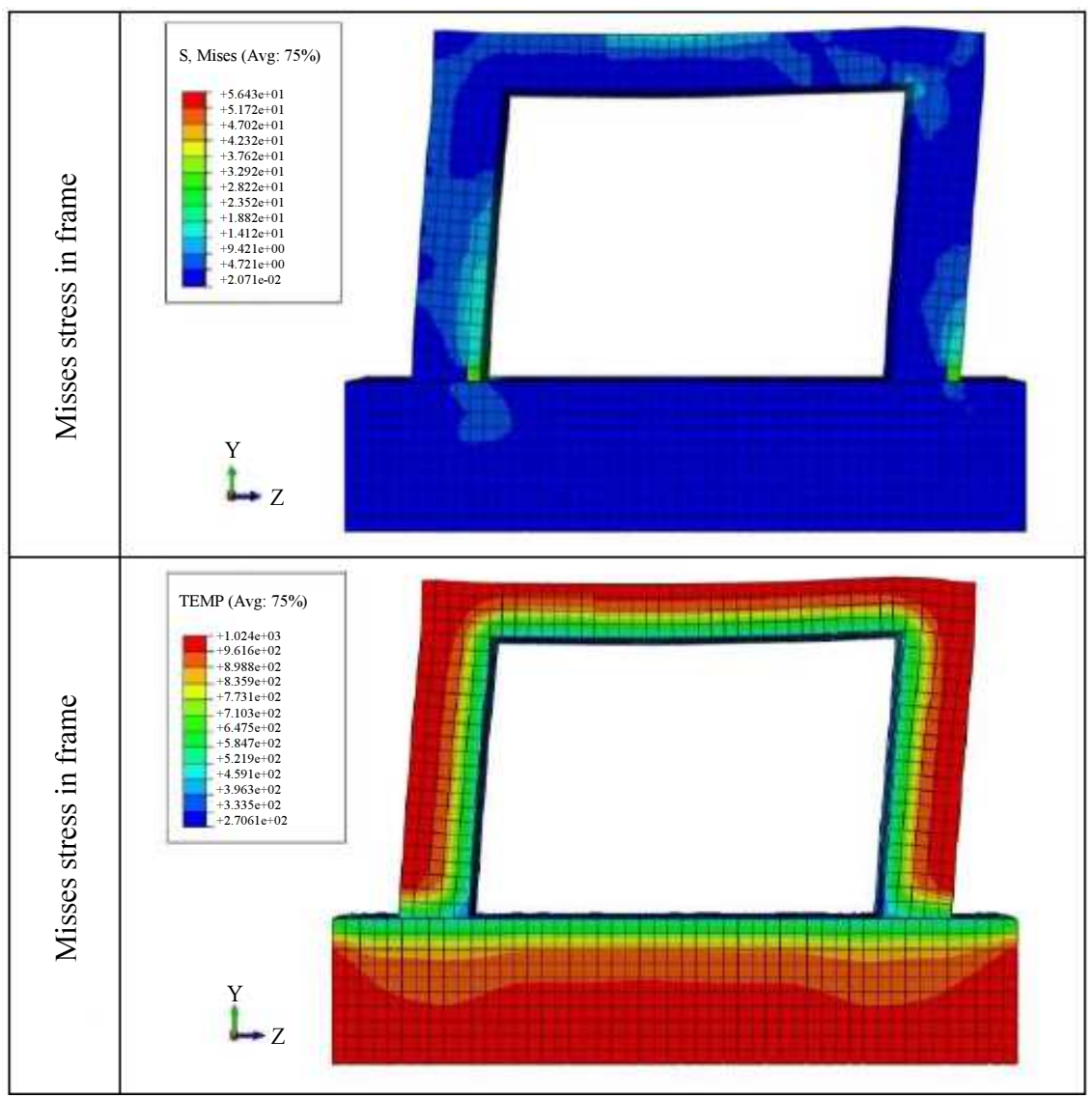

Fig. 8: Mises contours and frames thermal tension $-200^{\circ} \mathrm{C}$

By examining the contours of the von Mises concrete stress distribution at $400^{\circ} \mathrm{C}$, more elements were damaged and cracked compared to the $200^{\circ} \mathrm{C}$ state, in addition to the upper surface of the beam, at the beamcolumn connection and the base of the cracking column which the plastic joint is formed.
The force-displacement curve of the model under the temperature of $600^{\circ} \mathrm{C}$ is shown in Fig. 9. The maximum load capacity of this model was $18.64 \mathrm{KN}$ at test conditions. It can be seen that at this temperature the model has dropped its load capacity compared to $400^{\circ} \mathrm{C}$ by $25.13 \mathrm{KN}$. 
In Fig. 9, a temperature of $600^{\circ}$, a sharp deformation in the middle of the beam was happened which was faced with a sudden decrease in load and then relative increase. The reason for this can be, first, the flow of rebars and stirrups, which caused by sudden collapse and after the steel flood, the concrete core tolerates the load, which increases the relative capacity of the loading in the change of $55 \mathrm{~mm}$.

The maximum carrying capacity of the frame has been at $800^{\circ} \mathrm{C}, 7 / 74 \mathrm{KN}$. It can be seen that at this temperature, the model has dropped its load capacity by about $10.9 \mathrm{KN}$ at a temperature of $600^{\circ}$. After the full flow of the longitudinal and transverse beam, the RC beam also collapsed and the complete rupture in the beam occurred, especially in the middle of the span. This collapse in the system's load capacity has been highly influential. Then, due to the energy of the post-buckling system, the rest of the members of the load-bearing structure are tolerated and it can be noted that the main part of the load-bearing is the columns. It is shown in Fig. 10, the post-buckling behavior in the structure occurred after the displacement of $5 \mathrm{~mm}$ and extended to about $65 \mathrm{~mm}$.

The load-displacement curve of the model under the temperature of $1000^{\circ} \mathrm{C}$ is shown in Fig 10. The maximum carrying capacity of this model has been tested at $8 / 35 \mathrm{KN}$. It clear that at this temperature, the model has dropped in load capacity by a factor of $44 / 22$ $\mathrm{KN}$ to $200^{\circ} \mathrm{C}$.

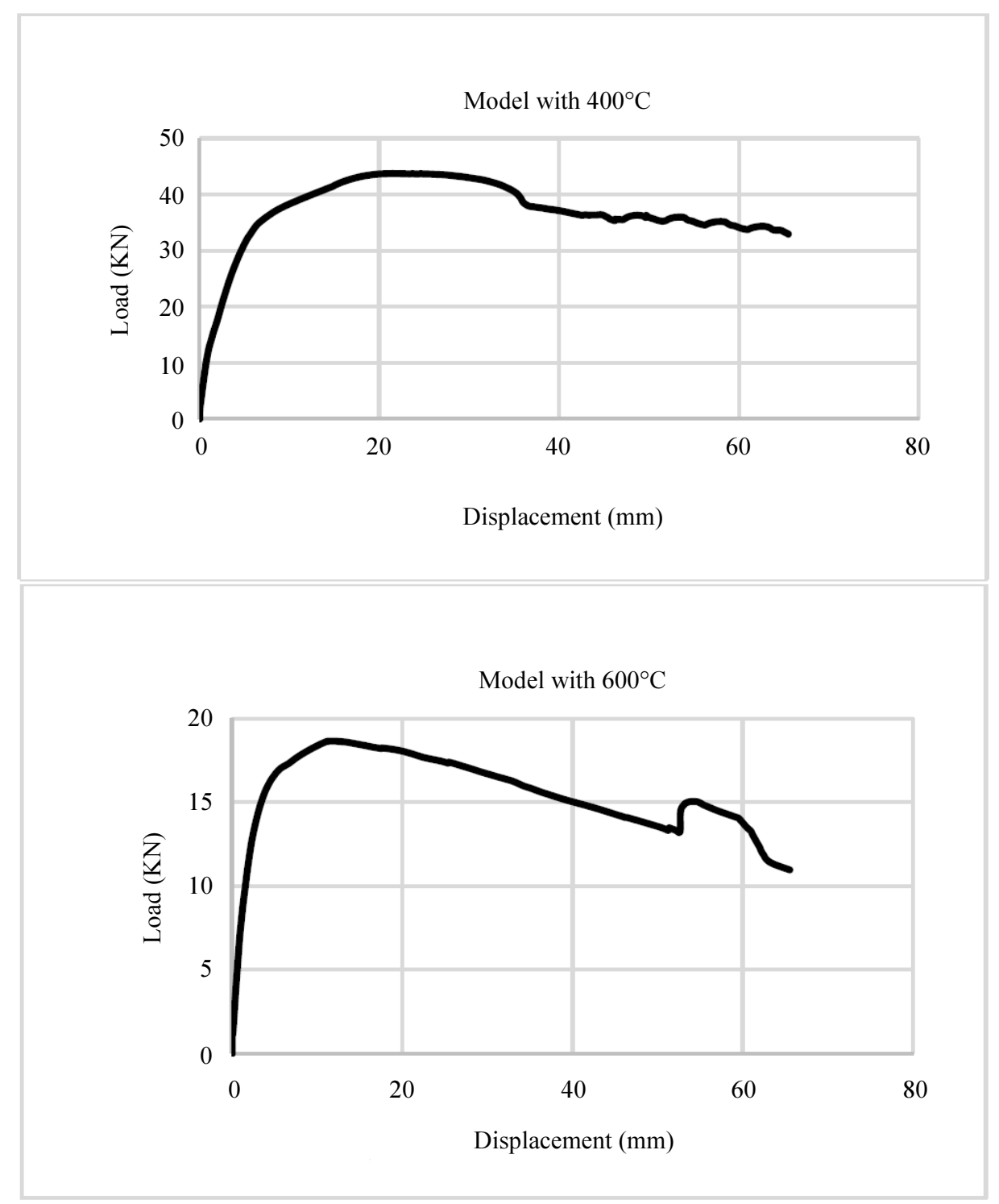

Fig. 9: load-displacement diagram of frame at temperature 400 and $600^{\circ} \mathrm{C}$ 


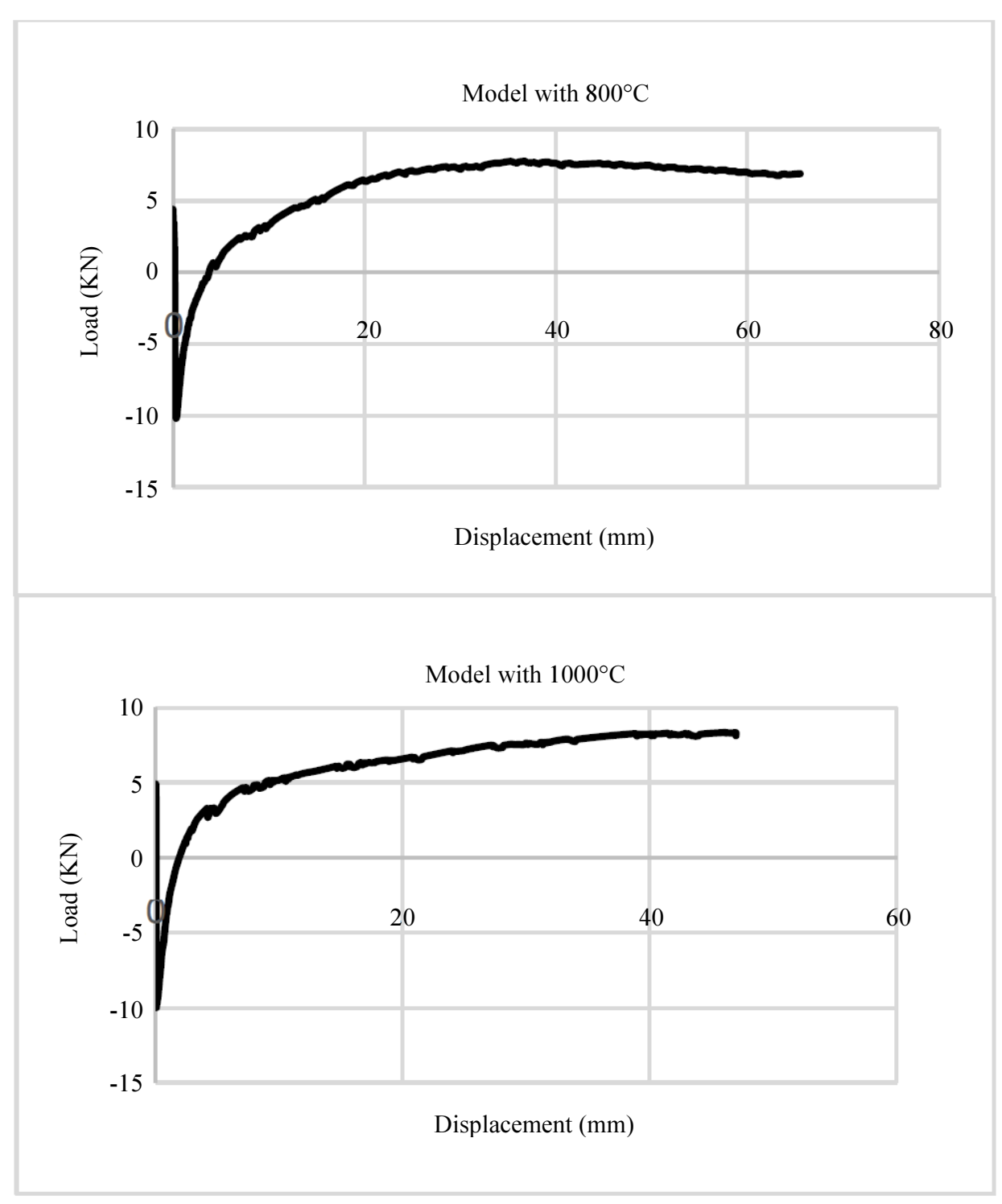

Fig. 10: Power curve - Frame change - Temperature 800 and $1000^{\circ}$

In the Fig. 11 precisely in the form and in the stress of the concrete masonry, a complete collapse occurred in the beam, due to the high temperature of the wide section of the column, which ran to the bottom of the column. As it can be seen in the tensions distribution of the bars, all the longitudinal and transverse are leaked and the concrete has the duty to withstand load. With the precision of Fig. 10, it can be seen that at the beginning of the thermal load, due to the collapse of the beam, there has been a sharp drop in the load capacity and, based on the buckling energy the system tolerates, a slight load capacity and formability have been improved. By analyzing the graph, it can be seen that at different times the loadings of the heat-affected elements will reduce the force and rupture, which will continue to tolerate concrete-loaded components. For this reason, distortion is in some areas of the chart.

In Fig. 12, the effect of heat on the frame load capacity is depicted during the heat increasing. With increasing temperature, the sample load capacity has decreased. Reductions in capacity up to $400^{\circ} \mathrm{C}$ are low, but at higher temperatures there has been a dramatic rise in loading capacity. At temperatures of 800 and 1000 degrees, this amount is only 7 and $8 \mathrm{KN}$.

Figure 13 shows the effect of the heat on the stiffness and shape of the frame. At $200^{\circ} \mathrm{C}$, the concrete has a higher capacity and the slope of the displacement-force shift curve has been declined. On the other hand, in the model under the temperature of 400 and 600 degrees, steel has been used to prevent 
the collapse of the frame. Due to this, it is in lower load capacity. But in models with temperatures of 800 and 1000 , the hardness dropped sharply due to the collapse of the system.
The reason for ductility increasing in the models with 400 and 600 degrees is to reduce the amount of displacement of the cracking threshold. The frame has the lowest degree of plasticity at $1000^{\circ} \mathrm{C}$.

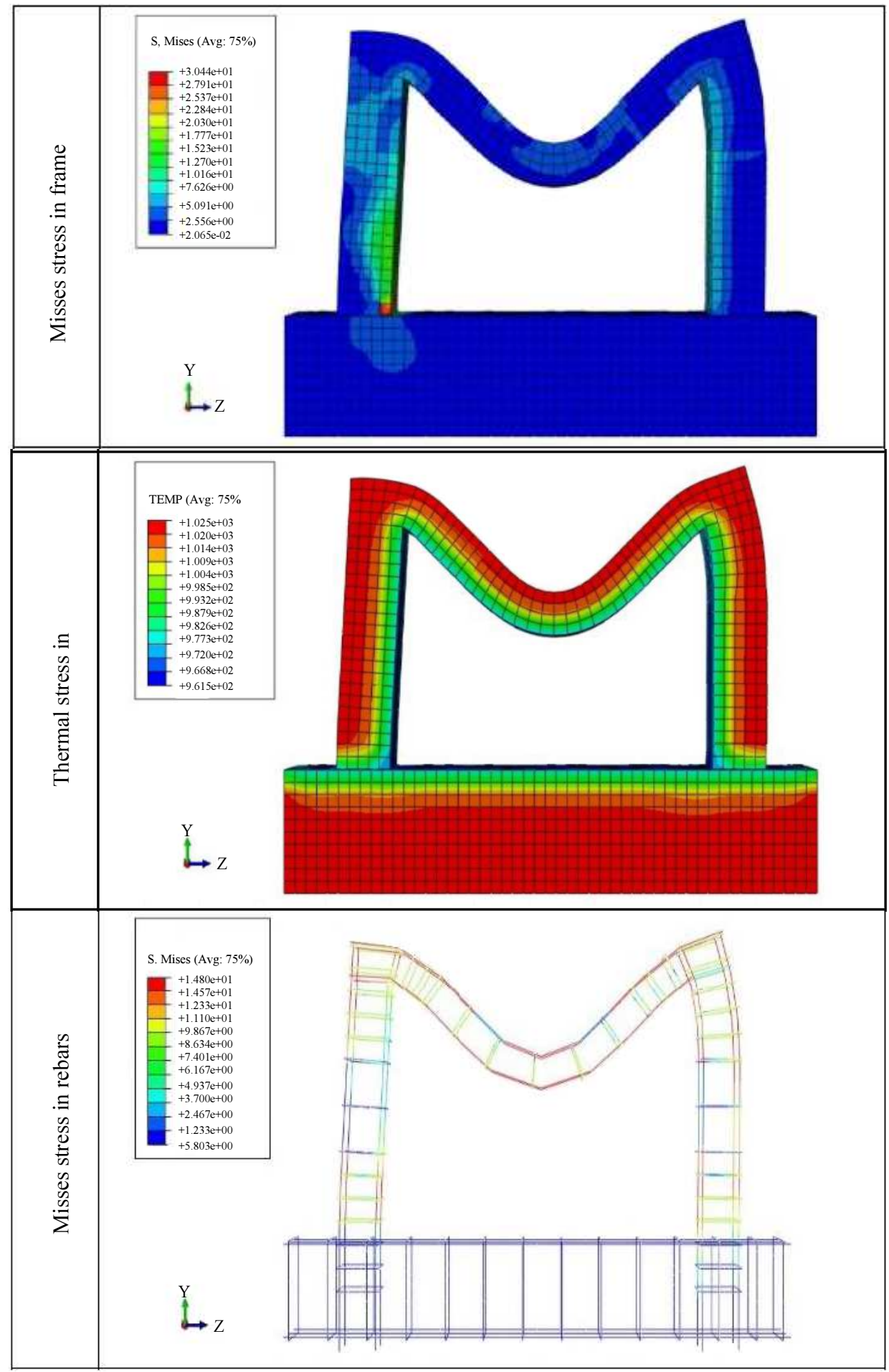

Fig. 11: Mises contours in frame and fittings and thermal stress in the frame $-1000^{\circ}$ 


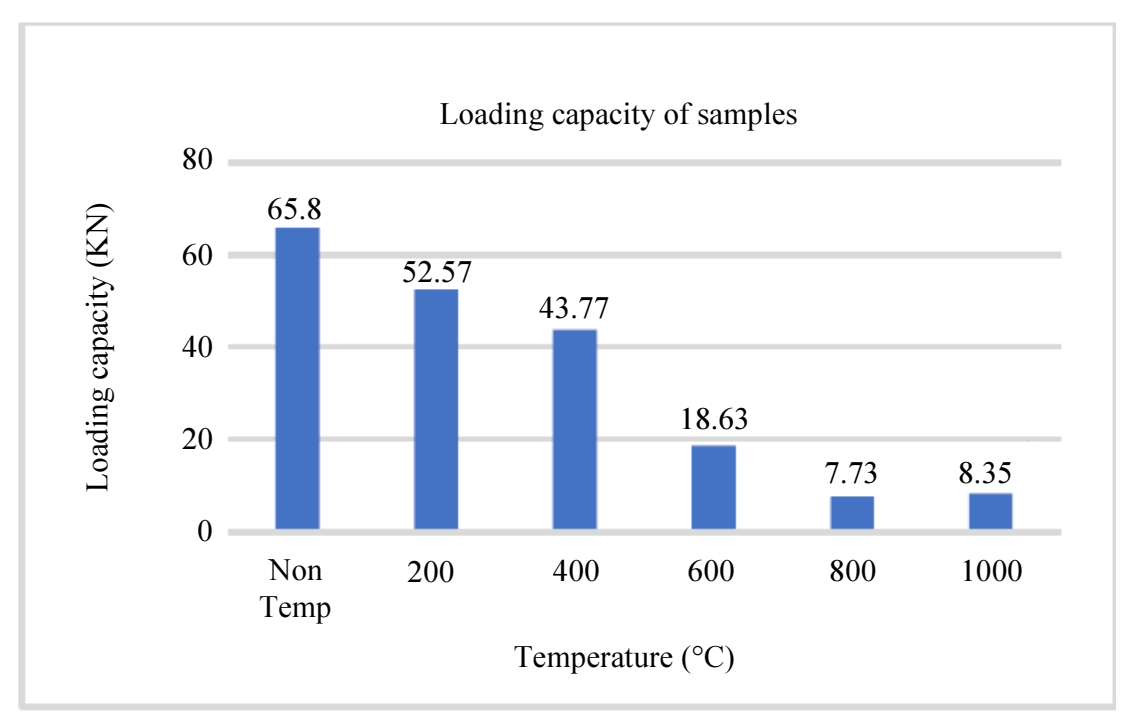

Fig. 12: Heat effect on frame bearing capacity

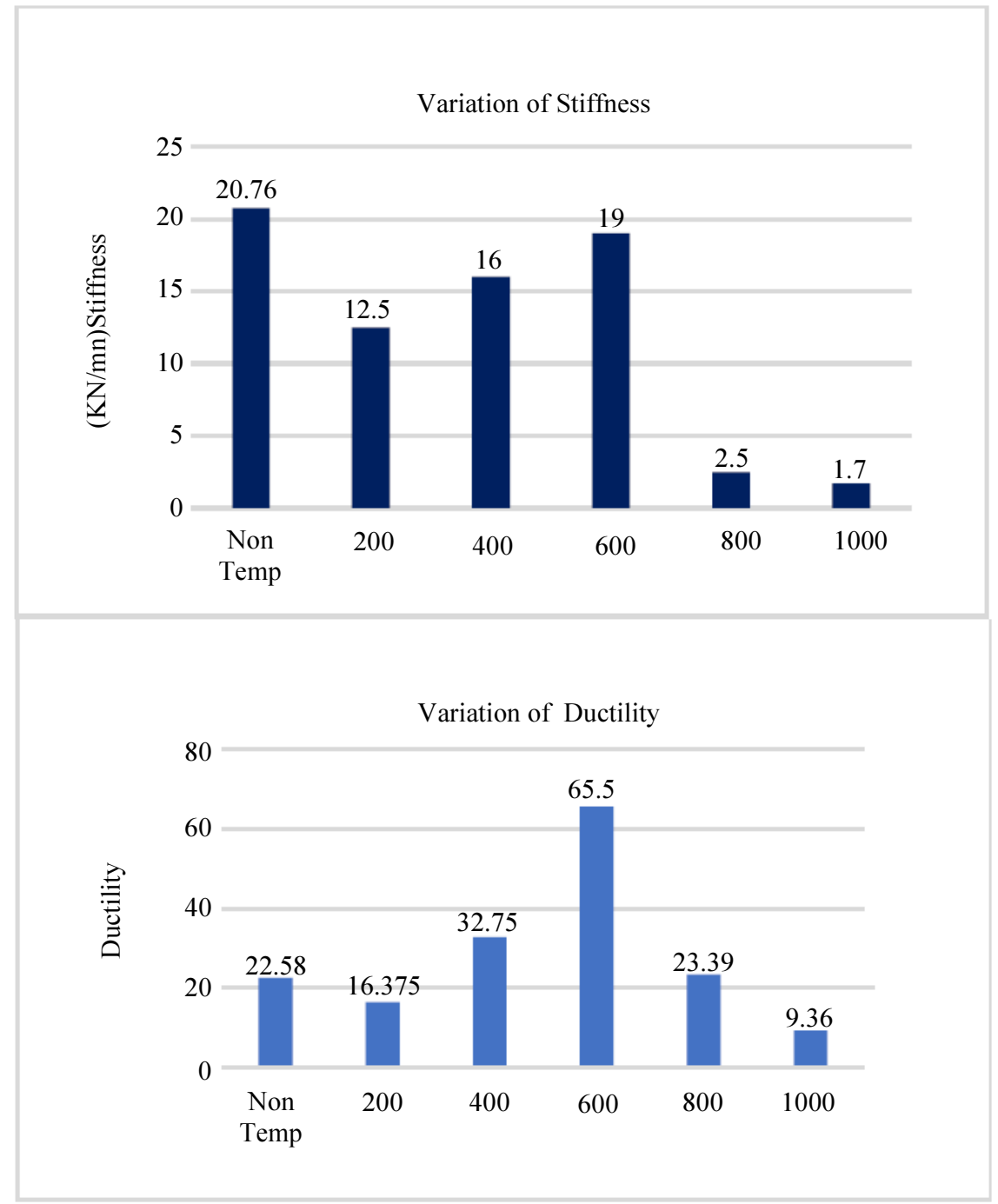

Fig. 13: Modifications of stiffness and ductility of samples during increasing temperature 


\section{Conclusion}

The results obtained from the sample capacity are as follows:

1. The weakest state without reinforcement under temperature of 1000 degrees has a carrying capacity of $8.35 \mathrm{KN}$

2. At temperatures of 200,400 and $600^{\circ} \mathrm{C}$, the frame is stable and under the temperature of 800 degrees, the frame is faced with the breakdown of transverse and longitudinal cross bars and in general, a sharp drop in capacity and ductility

3. At temperatures of $1000^{\circ} \mathrm{C}$, not only the longitudinal and transverse grooves flowed, but the concrete has also been completely ruptured

\section{Author's Contributions}

Reza Salehi: Performed modeling with FEM software and data analysis. Also, participated in writing the manuscript.

Abbas Akbarpour Nikghalb Rashti: Provided the research topic and guided the research development, experimental plan and data analysis. Also, participated in writing the manuscript.

\section{Ethics}

This article is an original research paper. There are no ethical issues that may arise after the publication of this manuscript.

\section{References}

Bangash, M.Y.H., Y.F. Al-Obaid and F.N. Bangash, 2014. Fire Engineering of Structures: Analysis and Design. 1st Edn., Springer Heidelberg New York, Dordrecht London, ISBN-10: 3642361536.
Fallahi, M., M. Haghighfar, R. Madandoust and S.S. Roudsari, 2018. Modelling of reinforced concrete frames with Infill walls under cyclic loading Strengthening with CFRP. J. Eng. Applied Sci.

Hemmati, A., A. Kheyroddin, M. Sharbatdar, Y. Park and M. Abolmaali, 2016. Ductile behavior of High Performance Fiber Reinforced Cementitious Composite (HPFRCC) frames. Construct. Build. Mat. 115: 681-689.

DOI: $10.1016 /$ j.conbuildmat.2016.04.078

Kodur, V.K.R., F.P. Cheng, T.C. Wang and M.A. Sultan, 2003. Effect of strength and fiber reinforcement on fire resistance of high-strength concrete columns. J. Structural Eng., 129: 1-22.

Priestley, M.J.N., F. Seible and G.M. Calvi, 1996. Seismic Design and Retrofit of Bridges. 1st Edn., John Wiley and Sons, Inc., New York, ISBN-10: 9780471579984.

Sayyar, S.R., A.H. Sameer, S.M. Soleimani and R. Madandoust, 2017. Evaluation of large-size reinforced concrete columns strengthened for axial load using fiber reinforced polymers. Eng. Structures J.

Roudsari, S.S. and S.M. Soleimani, 2015. Analytical study of reinforced concrete beams tested under impact loading. Proceedings of the 5th International Workshop on Performance, Protection and Strengthening of Structures Under Extreme Loading, (UEL' 15), pp: 620-627.

Sayyar, S.R., A.H. Sameer and S.M. Soleimani, 2018. Analytical study of reinforced concrete beams strengthened by FRP bars subjected to impact loading condition. A. J. Eng. Applied Sci. 